Check for updates

Cite this: Phys. Chem. Chem. Phys., 2020, 22, 15214

Received 23rd April 2020,

Accepted 1st June 2020

DOI: 10.1039/d0cp02181d

rsc.li/pccp

\section{Solvent effects on Li ion transference number and dynamic ion correlations in glyme- and sulfolane-based molten Li salt solvates $\dagger$}

\author{
Keisuke Shigenobu, ${ }^{a}$ Kaoru Dokko, (D) ${ }^{a}$ Masayoshi Watanabe (D) ${ }^{b}$ and \\ Kazuhide Ueno (D) *a
}

\begin{abstract}
The $\mathrm{Li}^{+}$transference number of electrolytes is one of the key factors contributing to the enhancement in the charge-discharge performance of Li secondary batteries. However, a design principle to achieve a high $\mathrm{Li}^{+}$transference number has not been established for liquid electrolytes. To understand the factors governing the $\mathrm{Li}^{+}$transference number $t_{\mathrm{L} \text { i, }}$ we investigated the influence of the ion-solvent interactions, $\mathrm{Li}$ ion coordination, and correlations of ion motions on the $\mathrm{Li}^{+}$transference number in glyme (Gn, $\left.n=1-4\right)$ and sulfolane (SL)-based molten Li salt solvate electrolytes with lithium bis(trifluoromethansulfonyl)amide (LiTFSA). For the 1:1 tetraglyme-LiTFSA molten complex, [Li(G4)][TFSA], the $\mathrm{Li}^{+}$transference number estimated using the potentiostatic polarisation method $\left(t_{\mathrm{Li}}^{\mathrm{PP}}=0.028\right)$ was considerably lower than that estimated using the self-diffusion coefficient data with pulsed filed gradient (PFG)-NMR ( $\left.t_{\mathrm{Li}}^{\mathrm{NMR}}=0.52\right)$. The dynamic ion correlations (i.e., cation-cation, anion-anion, and cation-anion cross-correlations) were determined from the experimental data on the basis of Roling and Bedrov's concentrated solution theory, and the results suggest that the strongly negative cross-correlations of the ion motions (especially for cation-cation motions) are responsible for the extremely low $t_{\mathrm{Li}}^{\mathrm{PP}}$ of [Li(G4)][TFSA]. In contrast, $t_{\mathrm{Li}}^{\mathrm{PP}}$ is larger than $t_{\mathrm{Li}}^{\mathrm{NMR}}$ in the SL-based electrolytes. The high $t_{\mathrm{Li}}^{\mathrm{PP}}$ of the SL-based electrolytes was ascribed to the substantially weaker anticorrelations of cation-cation and cation-anion motions. Whereas the translational motions of the long-lived

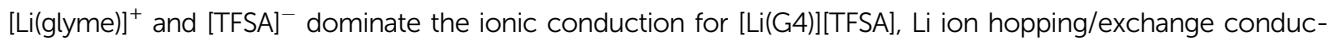
tion was reported to be prevalent in the SL-based electrolytes. The unique Li ion conduction mechanism is considered to contribute to the less correlated cation-cation and cation-anion motions in SL-based electrolytes.
\end{abstract}

\section{Introduction}

$\mathrm{The}_{\mathrm{Li}}^{+}$transference number, i.e., the ratio of $\mathrm{Li}$ ion mobility to the total ionic mobility, is one of the important parameters characterising the transport properties of electrolyte materials used in Li secondary batteries. With a growing demand for high-energy-density batteries with rapid charge-discharge capability, the significance of $\mathrm{Li}^{+}$transference number has been revisited and emphasised upon for designing a highly $\mathrm{Li}$ ion

\footnotetext{
${ }^{a}$ Department of Chemistry and Life Science, Yokohama National University, 79-5 Tokiwadai, Hodogaya-ku, Yokohama 240-8501, Japan. E-mail: ueno-kazuhide-rc@ynu.ac.jp; Fax: +81-45-339-3951; Tel: +81-45-339-3951

${ }^{b}$ Institute of Advanced Sciences, Yokohama National University, 79-5 Tokiwadai, Hodogaya-ku, Yokohama 240-8501, Japan

$\dagger$ Electronic supplementary information (ESI) available: Plots of the $\mathrm{Li}^{-\mathrm{Li}^{+}}$electrode potential against the natural logarithm of the Li salt concentration in the mixture of LiTFSA in the solvents, numerical data of the six experimentally obtained parameters for the calculation of Onsager transport coefficients, and the normalised transport coefficients. See DOI: 10.1039/d0cp02181d
}

conducting electrolytes, as recent studies on Li-ion battery modelling suggested a high- $\mathrm{Li}^{+}$transference number electrolyte enables a fast charge-discharge capability even with relatively low ionic conductivity, ${ }^{1}$ and suppression of the lithium dendrite growth at the Li metal anode. ${ }^{2}$ All solid state batteries using sulphide-based solid electrolytes with $\mathrm{Li}^{+}$transference number of unity demonstrated very fast charge-discharge within a few minutes ${ }^{3}$ and highenergy long-cycling with lithium metal anode. ${ }^{4}$

Molten Li salt solvates or liquid electrolytes with nearly saturated $\mathrm{Li}$ salt concentrations are also regarded as a prospective electrolyte material for Li secondary batteries; this is because various types of highly concentrated electrolyte systems, ranging from aqueous to non-aqueous and ionic liquid (IL), have shown improved rate capability, long-term cycling stability, and high Coulombic efficiency. ${ }^{5-13}$ In previous studies, we investigated the $\mathrm{Li}$ ion coordination structure and ionic transport properties of two types of molten $\mathrm{Li}$ salt solvates:oligoether glyme $\left(\mathrm{CH}_{3} \mathrm{O}\left(\mathrm{CH}_{2}\right.\right.$ $\left.\left.\mathrm{CH}_{2} \mathrm{O}\right)_{n} \mathrm{CH}\right)^{-14-16}$ and sulfolane (SL)-based electrolytes. ${ }^{17,18}$ In the former case, a 1:1 molar mixture of tetraglyme (G4) and lithium 
bis(trifluoromethanesulfonyl)amide (LiTFSA) forms a thermallystable molten Li salt solvate ([Li(G4)][TFSA]) comprising a crownether like $[\mathrm{Li}(\mathrm{G} 4)]^{+}$complex cation and a TFSA $^{-}$anion, and it behaves like ILs. [Li(G4)][TFSA] was found to exhibit a $\mathrm{Li}^{+}$-limiting current density one order of magnitude higher than that of a binary mixture electrolyte of $\mathrm{IL}$ and $\mathrm{Li}$ salt, leading to the enhanced rate capability of the $\mathrm{Li} / \mathrm{LiCoO}_{2}$ cell. ${ }^{14,19}$ In the latter case, i.e., for SL-based molten $\mathrm{Li}$ salt solvates, the $\mathrm{Li}$ ion is observed to diffuse faster than SL and the anion; this indicates that the Li ion hopping/exchange conduction mechanism contributes significantly to the ionic conduction. A unique chain-like $\cdots \mathrm{SL} \cdot \mathrm{Li}^{+} \cdots \mathrm{SL} \cdot \cdots \mathrm{Li}^{+} \cdots$ coordination structure was suggested to be involved in the extraordinary Li ion conduction. ${ }^{17}$ The SL-based molten Li salt solvates showed a better rate capability of the $\mathrm{Li} / \mathrm{S}$ cell compared with the cell using $[\mathrm{Li}(\mathrm{G} 4)][$ TFSA $] .{ }^{18,20}$

The higher $\mathrm{Li}^{+}$transference number of the concentrated electrolytes has been considered to be the key reason for the enhanced rate capability of Li secondary batteries. Nevertheless, the relationship between the molecular structure and $\mathrm{Li}^{+}$ transference number remains to be clarified. Furthermore, there is no established guideline for designing liquid electrolytes with a high $\mathrm{Li}^{+}$transference number. For solid polymer electrolytes, Balsara and Newman systematically studied crosscorrelations of ion motions by introducing Stefan-Maxwell diffusion coefficients and their relevance to the $\mathrm{Li}^{+}$transference number. ${ }^{21-23}$ Woolf and Harris have also investigated the correlated ion motions in terms of velocity cross-correlation functions for aqueous electrolyte solutions. ${ }^{24}$ Although a few studies have focused on the ion correlations for Li ion conducting organic electrolyte solutions, recent seminal works based on Onsager reciprocal relations combined with the linear response theory by Roling and Bedrov has revealed the importance of the interionic correlations to the $\mathrm{Li}^{+}$transference number for molten Li salt solvates..$^{25-27}$ For [Li(G4)][TFSA], Roling and Bedrov suggested that the strongly anti-correlated ion dynamics were due to the constraint of momentum conservation for the long-lived $[\mathrm{Li}(\mathrm{G} 4)]^{+}$complex cation and the TFSA $^{-}$anion, resulting in an extremely low $\mathrm{Li}^{+}$transference numbers under anion-blocking conditions.

Here, we studied effect of ion-solvent interactions and Li ion coordination structure on the $\mathrm{Li}^{+}$transference number for the glyme- and SL-based molten Li salt solvates. The dynamic correlations of ions were also experimentally determined on the basis of Roling and Bedrov's concentrated electrolyte theory. ${ }^{26,27}$ The relationship between the ionic correlations and $\mathrm{Li}^{+}$transference number was discussed in relation to $\mathrm{Li}$ ion coordination structure and possible ion transport mechanism.

\section{Experimental}

\subsection{Materials}

Purified diglyme (G2), triglyme (G3), and tetraglyme (G4) (water content $<50 \mathrm{ppm}$ ) were supplied by Nippon Nyukazai. Monoglyme (G1, battery grade $<50 \mathrm{ppm}$ ) and sulfolane (SL, battery grade $<50 \mathrm{ppm}$ ) were purchased from Kishida Chemical.
Lithium bis(trifluoromethanesulfonyl)amide (Li[TFSA], $>99.9 \%$, water content $<100 \mathrm{ppm}$ ) was provided by Solvay Japan. All molten Li salt solvates were prepared in an inert argon-filled glove box $\left(\left[\mathrm{H}_{2} \mathrm{O}\right]<1 \mathrm{ppm} ;\left[\mathrm{O}_{2}\right]<1 \mathrm{ppm}\right)$.

\subsection{Measurements}

Two different $\mathrm{Li}^{+}$transference numbers were determined by either potentiostatic polarisation method or self-diffusion coefficients obtained from PFG-NMR. For the potentiostatic polarisation method, the experiments were performed using an $\mathrm{Li}$ symmetric cell. A porous glass filter paper (Advantec, GA55, $17 \mathrm{~mm}$ in diameter) impregnated with the liquid electrolyte was placed between two Li foil electrodes (Honjo Metal, $16 \mathrm{~mm}$ in diameter) in a 2032-coin-type cell. Impedance spectra were measured in the frequency range of $100 \mathrm{mHz}-1 \mathrm{MHz}$ with a perturbation voltage amplitude of $10 \mathrm{mV}$, using a potentiostat (Solartron Analytical, ModuLab XM ECS). The impedance measurements were preliminarily performed every hour prior to the potentiostatic polarisation to ensure the stabilisation of $\mathrm{Li}$ electrode interface. The time dependence of current was monitored during the potentiostatic polarisation, with a potential step of $10 \mathrm{mV}$. After the current reached the steady state, impedance spectra were measured again, as prescribed in the literature. $^{28,29}$ The experimental details for PFG-NMR are available in our previous report. ${ }^{15}$ The salt diffusion coefficients $\left(D_{\text {salt }}\right)$ used for calculating Onsager transport coefficients were determined using the same Li symmetric coin cell, as described in the literature. ${ }^{22}$ The cell was polarised to $10 \mathrm{mV}$ in the potentiostatic mode and the relaxation of the cell potential was recorded after the applied potential was removed. The potential relaxation was fitted using a single exponential decay function to determine $D_{\text {salt }}$ (see ESI, $\dagger$ in detail). The electrode potentials of $\mathrm{Li} / \mathrm{Li}^{+}$were measured with the help of the reference electrode ( $\mathrm{Li} / \mathrm{Li}^{+}$in $1 \mathrm{~mol} \mathrm{dm}{ }^{-3} \mathrm{Li}[\mathrm{TFSA}] / \mathrm{G} 3$ ) using a multi-compartment concentration cell. ${ }^{30}$ Vycor glass was used for the junction between the reference electrolyte and the sample electrolytes. The potential was recorded using a multi-channel potentiostat (BioLogic, VSP300). A slope $\mathrm{d} \varphi / \mathrm{d} \ln (c)$ at given concentration was obtained from the slope of the concentration dependence of the concentration cell potential (Fig. S1, ESI $\dagger$ ). ${ }^{26}$ All the above measurements were performed at $30{ }^{\circ} \mathrm{C}$, unless otherwise noted.

\section{Results and discussion}

\subsection{Estimation of $\mathrm{Li}^{+}$transference number}

Several methods have been proposed for estimating $\mathrm{Li}^{+}$transference number of $\mathrm{Li}$ ion conducting electrolytes, such as potentiostatic polarisation, galvanostatic polarisation, verylow-frequency impedance spectroscopy, concentration cell method, PFG-NMR, and electrophoretic NMR, although there are inherent restrictions for each method (e.g., sample limitations and cumbersome procedures). ${ }^{25,31,32}$ In previous publications, we reported the apparent $\mathrm{Li}^{+}$transference number derived from PFG-NMR $\left(t_{\mathrm{Li}}^{\mathrm{NMR}}\right)$ for the glyme- and SL-based molten Li salt solvates electrolytes. ${ }^{15,18}$ Here, $t_{\mathrm{Li}}^{\mathrm{NMR}}$ is simply 
defined as the ratio of self-diffusion coefficients of $\mathrm{Li}$ ion $\left(D_{\mathrm{Li}}\right)$ and TFSA anion $\left(D_{\text {anion }}\right)$,

$$
t_{\mathrm{Li}}^{\mathrm{NMR}}=\frac{D_{\mathrm{Li}}}{D_{\mathrm{Li}}+D_{\text {anion }}}
$$

The PFG-NMR method relies on Nernst-Einstein equation, assuming that the ions are completely dissociated and move independently, as postulated for ideal dilute electrolyte solutions. This would not rigorously hold for the molten Li salt solvate electrolytes with extremely high salt concentrations, and therefore, $t_{\mathrm{Li}}^{\mathrm{NMR}}$ may be dissimilar to the realistic $\mathrm{Li}^{+}$transference number.

The potentiostatic polarisation combined with electrochemical impedance spectroscopy ${ }^{28,29}$ is facile and a relatively versatile method, and has been adopted for various electrolytes, ranging from polymeric to liquid systems. The $\mathrm{Li}^{+}$transference number based on this method $\left(t_{\mathrm{Li}}^{\mathrm{PP}}\right)$ was obtained as follows:

$$
t_{\mathrm{Li}}^{\mathrm{PP}}=\frac{I_{\mathrm{SS}}\left(V_{\mathrm{DC}}-I_{\mathrm{Ohm}} R_{i, 0}\right)}{I_{\mathrm{Ohm}}\left(V_{\mathrm{DC}}-I_{\mathrm{SS}} R_{i, \mathrm{SS}}\right)}
$$

where $V_{\mathrm{DC}}$ is the constant applied voltage, $I_{\mathrm{Ohm}}$ and $I_{\mathrm{SS}}$ are initial and steady-state current during the polarisation, and $R_{\mathrm{i}, 0}$ and $R_{\mathrm{i}, \mathrm{ss}}$ are the initial and steady-state interfacial resistance at the Li metal electrodes, respectively. In previous studies, $t_{\mathrm{Li}}^{\mathrm{PP}}$ has often been calculated using an initial current value, $I_{0}$, determined using the initial data point of the polarisation current curve. However, as noted in recent research by Balsara et al. ${ }^{23}$ and Roling et al. ${ }^{25} I_{0}$ may not be accurate in some cases since it strongly depends on the data sampling time. In accordance with the report by Balsara et al., ${ }^{23}$ we used another initial current calculated by the Ohm's law, $I_{\mathrm{Ohm}}=V_{\mathrm{DC}} /\left(R_{\mathrm{bulk}}+R_{\mathrm{i}, 0}\right)$, for the calculation of $t_{\mathrm{Li}}^{\mathrm{PP}}$. Specifically, $t_{\mathrm{Li}}^{\mathrm{PP}}$ can also be approximated as the realistic $\mathrm{Li}^{+}$transference number only for dilute and completely dissociated electrolyte systems. However, $t_{\mathrm{Li}}^{\mathrm{PP}}$, also referred to as "current fraction" in the literature, ${ }^{23}$ is practically useful for characterising the $\mathrm{Li}$ ion transport property of electrolytes because this value is measurable at any salt concentrations and is determined under anion-blocking conditions, similar to the saturation in lithium ion batteries.
$t_{\mathrm{Li}}^{\mathrm{PP}}$ affects the degree of concentration polarisation in the electrochemical cell with a small DC potential, and lower $t_{\mathrm{Li}}^{\mathrm{PP}}$ implies a larger concentration gradient of Li salt in the steady state.

With the results of polarisation current curves ( $I_{\mathrm{Ohm}}$ and $\left.I_{\mathrm{SS}}\right)$ and impedance spectra $\left(R_{\mathrm{i}, 0}\right.$ and $\left.R_{\mathrm{i}, \mathrm{SS}}\right)$ for the Li symmetric cell as shown in Fig. 1, $t_{\mathrm{Li}}^{\mathrm{PP}}$ was found to be 0.68 for a $1: 2$ molar mixture of LiTFSA and SL ([Li(SL) 2$][$ TFSA $])$. Similarly, $t_{\mathrm{Li}}^{\mathrm{PP}}$ for [Li(G4)][TFSA] was found to be 0.028 . These values reasonably agree with the reported $t_{\mathrm{Li}}$ values for $\left[\mathrm{Li}(\mathrm{SL})_{2}\right][\mathrm{TFSA}]\left(0.71^{20}\right)$ and for $[\mathrm{Li}(\mathrm{G} 4)]\left[\right.$ TFSA] $\left(0.026^{25}\right.$ and $\left.0.03^{20}\right)$ determined by verylow-frequency impedance method, confirming the validity of $t_{\mathrm{Li}}^{\mathrm{PP}}$ measured by the potentiostatic polarisation method.

Here, we studied the influence of ion-solvent interaction and $\mathrm{Li}$ ion coordination structure on the $\mathrm{Li}^{+}$transference numbers for the glyme- and SL-based molten Li salt solvate electrolytes. For the glyme systems, we examined the molten $\mathrm{Li}$ salt solvates with different glyme chain lengths (G1 to G4), while adjusting the molar ratio of oxygen atoms of the solvent molecules to $\mathrm{Li}$ ions $\left([\mathrm{O}] /\left[\mathrm{Li}^{+}\right]\right)$to be 4 or $5 .{ }^{16}\left[\mathrm{Li}(\mathrm{SL})_{2}\right][\mathrm{TFSA}]$ and $\left[\mathrm{Li}(\mathrm{SL})_{3}\right][\mathrm{TFSA}]$ showing a unique Li ion transport via a dominant $\mathrm{Li}$ ion hopping/exchange mechanism ${ }^{17,18}$ were also studied for comparison.

The $\mathrm{Li}^{+}$transference numbers $\left(t_{\mathrm{Li}}^{\mathrm{NMR}}\right.$ and $\left.t_{\mathrm{Li}}^{\mathrm{PP}}\right)$ of the molten $\mathrm{Li}$ salt solvates are listed in Table 1 . Whereas the glyme-based electrolytes showed a relatively high $t_{\mathrm{Li}}^{\mathrm{NMR}}$ of roughly $0.5-0.6$, irrespective of the chain length of the glyme molecules, $t_{\mathrm{Li}}^{\mathrm{PP}}$ was one order of magnitude lower for [Li(G3)][TFSA] and [Li(G4)][TFSA] with longer glymes compared with those for $\left[\mathrm{Li}(\mathrm{G} 1)_{2}\right][\mathrm{TFSA}]$ and $[\mathrm{Li}(\mathrm{G} 1)(\mathrm{G} 2)][\mathrm{TFSA}]$ with shorter glymes. This dependence of $t_{\mathrm{Li}}^{\mathrm{PP}}$ on the chain length appears to be relevant to the classification of the molten $\mathrm{Li}$ salt solvates into solvate ionic liquids. [Li(G3)][TFSA] and [Li(G4)][TFSA] were regarded as good solvate ionic liquids considering aspects such as the formation of crown ether-like, long-lived [Li(glyme $)]^{+}$complex cation and negligible amounts of uncoordinated glyme; in contrast, the molten Li salt solvates with the shorter glyme, such as $\left[\mathrm{Li}(\mathrm{G} 1)_{2}\right][\mathrm{TFSA}]$, were classified into concentrated solutions in which the complex cations are not stable owing to a weaker chelate effect. ${ }^{16}$
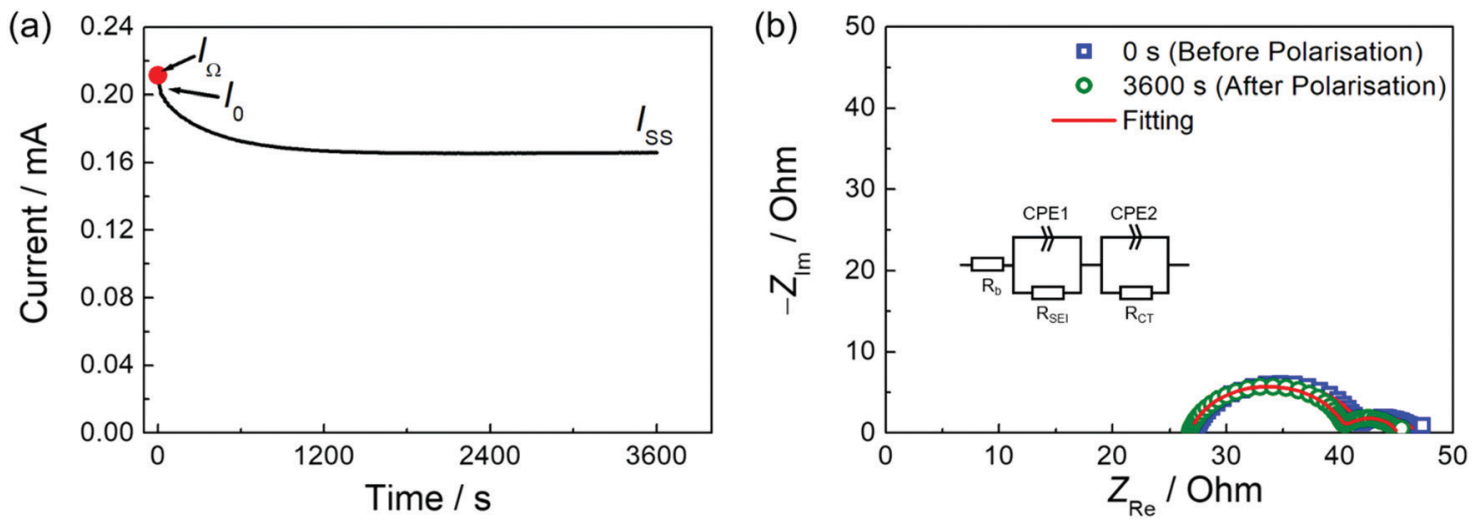

Fig. 1 (a) Polarisation current curve and (b) Nyquist plots of an $\mathrm{Li}^{\prime} \mathrm{Li}^{+}$symmetric cell using $\left[\mathrm{Li}(\mathrm{SL})_{2}\right][\mathrm{TFSA}]$ before and after potentiostatic polarisation. The equivalent circuit used for fitting the Nyquist plots is shown in the inset. 
Table $1 t_{\mathrm{Li}}^{\mathrm{NMR}}, t_{\mathrm{Li}}^{\mathrm{PP}}$ and $t_{\mathrm{Li}}^{\mathrm{MD}}$ for the glyme- and SL-based molten Li salt solvates. $t_{\mathrm{L}}^{\mathrm{NMR}}$ values for the glyme- and SL-based electrolytes were obtained from ref. 16 and 18 , respectively, except for [Li(G1)(G2)][TFSA]. $t_{\mathrm{Li}}^{\mathrm{MD}}$ was obtained from ref. 26

\begin{tabular}{llll}
\hline Sample & $t_{\mathrm{Li}}^{\mathrm{NMR}}$ & $t_{\mathrm{Li}}^{\mathrm{PP}}$ & $t_{\mathrm{Li}}^{\mathrm{MD}}$ \\
\hline$[\mathrm{Li}(\mathrm{G} 3)][\mathrm{TFSA}]$ & 0.61 & 0.028 & 0.10 \\
{$[\mathrm{Li}(\mathrm{G} 4)][\mathrm{TFSA}]$} & 0.52 & 0.028 & 0.06 \\
{$\left[\mathrm{Li}(\mathrm{G} 1)_{2}\right][\mathrm{TFSA}]$} & 0.54 & 0.35 & 0.30 \\
{$[\mathrm{Li}(\mathrm{G} 1)[\mathrm{G} 2)][\mathrm{TFSA}]$} & 0.48 & 0.31 & 0.26 \\
{$\left[\mathrm{Li}(\mathrm{SL})_{2}\right][$ TFSA } & 0.61 & 0.68 & - \\
{$\left[\mathrm{Li}(\mathrm{SL})_{3}\right][$ TFSA] } & 0.57 & 0.69 & -
\end{tabular}

Molecular dynamics (MD) simulations by Bedrov et al. demonstrated a good correlation between the glyme chain length and the $\mathrm{Li}^{+}$transference number $\left(t_{\mathrm{Li}}^{\mathrm{MD}}\right)$ of the glyme-based molten $\mathrm{Li}$ salt solvates under anion-blocking conditions. ${ }^{26}$ The $t_{\mathrm{Li}}^{\mathrm{MD}}$ value decreases with increasing chain length of the glyme from G1 to G4 as seen in Table 1. The general tendency observed in our experimental $t_{\mathrm{Li}}^{\mathrm{PP}}$ is in accordance with the glyme chain length dependence of $t_{\mathrm{Li}}^{\mathrm{MD}}$ estimated by Bedrov et al.

Both $t_{\mathrm{Li}}^{\mathrm{NMR}}$ and $t_{\mathrm{Li}}^{\mathrm{PP}}$ for the SL-based electrolytes were higher than those of the glyme-based electrolytes. The high $t_{\mathrm{Li}}^{\mathrm{PP}}$ suggests that the Li salt concentration gradient develops to a lesser extent in the SL-based electrolytes. In the SL-based molten $\mathrm{Li}$ salt solvates, the two oxygen atoms of one SL coordinates to two different neighbouring Li ions forming an SL-bridged, chainlike $\mathrm{Li}$ ion coordination structure $\left(\cdots \mathrm{SL} \cdots \mathrm{Li}^{+} \cdots \mathrm{SL} \cdots \mathrm{Li}^{+} \cdots\right){ }^{17,18}$ The unique $\mathrm{Li}$ ion coordination structure may play a pivotal role in displaying the high $t_{\mathrm{Li}}^{\mathrm{PP}}$ as well as the unusual self-diffusion behaviour of Li ions (diffusing faster than SL and TFSA anions).

Another noteworthy aspect in Table 1 is a discrepancy between $t_{\mathrm{Li}}^{\mathrm{NMR}}$ and $t_{\mathrm{Li}}^{\mathrm{PP}}$ for each electrolyte. $t_{\mathrm{Li}}^{\mathrm{PP}}$ was considerably lower than $t_{\mathrm{Li}}^{\mathrm{PP}}$ for [Li(G3)][TFSA] and [Li(G4)][TFSA]. The recent studies $^{25,26,33,34}$ suggested that the extremely low $t_{\mathrm{Li}}^{\mathrm{PP}}$ as compared with $t_{\mathrm{Li}}^{\mathrm{NMR}}$ for the solvate ionic liquids, [Li(G3)][TFSA] and [Li(G4)][TFSA], is attributable to the remarkable anti-correlated motions of the ions, which is a consequence of the constraint of momentum conservation for the long-lived [Li(glyme) $]^{+}$complex cation and $\mathrm{TFSA}^{-}$anion under the anion blocking conditions. The momentum conservation of the ions is achieved solely by the momentum exchange of the ions, as with the cases for solventfree molten salts and ionic liquids. ${ }^{35,36}$ The previous MD simulation study also suggested that the anti-correlated motions of the ions can be mitigated in the shorter glyme systems since a more frequent solvent exchange between the unstable [Li(glyme)] complex cations contributes to the momentum conservation. ${ }^{26}$ This would result in $t_{\mathrm{Li}}^{\mathrm{PP}}$ being a little lower than $t_{\mathrm{Li}}^{\mathrm{NMR}}$ for $\left[\mathrm{Li}(\mathrm{G} 1)_{2}\right][\mathrm{TFSA}]$ and $[\mathrm{Li}(\mathrm{G} 1)(\mathrm{G} 2)][\mathrm{TFSA}]$. In contrast, the $t_{\mathrm{Li}}^{\mathrm{PP}}$ was higher than $t_{\mathrm{Li}}^{\mathrm{NMR}}$ for [Li(SL) $\left.)_{2}\right][\mathrm{TSFA}]$ and [Li(SL) $\left.)_{3}\right][\mathrm{TFSA}]$. The same trend was also observed for the SL-based concentrated electrolytes with lithium bis(fluorosulfonyl)amide. ${ }^{34,37}$ This implies that the dynamic ion correlations positively affected the $\mathrm{Li}^{+}$transference number under anion blocking conditions $\left(t_{\mathrm{Li}}^{\mathrm{PP}}\right)$ in the SL-based electrolytes. The effects of the dynamic ion correlations on the $\mathrm{Li}^{+}$ transference numbers are investigated in detail in the following section.

\subsection{Dynamic correlations of the ions}

The dynamic ion correlations in the molten Li salt solvates were experimentally determined to understand their contribution to ionic conductivity and to clarify the difference in ionic transport behaviour in the molten Li salt solvates. In this work, the Onsager transport coefficients were employed to evaluate the interionic correlations according to Roling and Bedrov et al. ${ }^{25,26}$ In the Onsager transport formalism, the ionic conductivity $\sigma_{\text {ion }}$ is described as

$$
\sigma_{\text {ion }}=\sigma_{++}+\sigma_{--}-2 \sigma_{+-}
$$

Two transport coefficients for cation and anion, $\sigma_{++}$and $\sigma_{--}$, can be further divided into self-terms and distinct terms, respectively, and the ionic conductivity $\sigma_{\text {ion }}$ is given as follows:

$$
\sigma_{\text {ion }}=\sigma_{+}^{\text {self }}+\sigma_{+}^{\text {distinct }}+\sigma_{-}^{\text {self }}+\sigma_{--}^{\text {distinct }}-2 \sigma_{+-}
$$

All the Onsager transport coefficients $\left(\sigma_{++}, \sigma_{--}\right.$and $\left.\sigma_{+-}\right)$can be estimated from experimentally determined quantities, $\sigma_{\text {ion }}$, $t_{\mathrm{Li}}^{\mathrm{PP}}, D_{\text {salt }}$ and $\mathrm{d} \Delta \varphi / \mathrm{d} \ln (c)$ and these experimental data were listed in Table S1 (ESI $\dagger)$. The self-terms, $\sigma_{+}^{\text {self }}$ and $\sigma_{-}^{\text {self }}$, are obtained from the Nernst-Einstein equation using selfdiffusion coefficients of Li ions $\left(D_{\mathrm{Li}}\right)$, and the anions $\left(D_{\text {anion }}\right),{ }^{26}$ and the distinct terms can be calculated by simply subtracting $\sigma_{+}^{\text {self }}$ (and $\sigma_{-}^{\text {self }}$ ) from $\sigma_{++}$(and $\sigma_{--}$). The detailed procedure for estimating the transport coefficients is described in Supplementary Information. The sign of $\sigma_{++}^{\text {distinct }}, \sigma_{--}^{\text {distinct }}$, and $\sigma_{+-}$is closely related to the dynamic cross-correlations of cationcation, anion-anion, and cation-anion, respectively. The sign of the cross-correlations becomes positive and negative for correlated and anti-correlated ion motions, respectively, while the cross-correlations of zero represent non-correlated interionic dynamics as assumed in ideal electrolyte solutions.

Fig. 2 shows the normalised coefficients $\left(\sigma_{+}^{\text {self }}, \sigma_{-}^{\text {self }}, \sigma_{++}^{\text {distinct }}\right.$, $\sigma_{--}^{\text {distinct }}$, and $\sigma_{+-}$divided by $\sigma_{\text {ion }}$ ) to illustrate the contribution of the dynamic correlations to the total ionic conductivity. The numeric data for these coefficients are also listed in Table S2 (ESI $\dagger$ ). As shown in the Fig. 2a and b, for the solvate ionic liquids, $[\mathrm{Li}(\mathrm{G} 3)][\mathrm{TFSA}]$ and $[\mathrm{Li}(\mathrm{G} 4)][\mathrm{TFSA}]$, all the crosscorrelations $\left(\sigma_{++}^{\text {distinct }} / \sigma_{\text {ion }}, \sigma_{--}^{\text {distinct }} / \sigma_{\text {ion }}\right.$, and $\left.\sigma_{+-} / \sigma_{\text {ion }}\right)$ are negative, indicating that the cation-cation, anion-anion, and cation-anion motions are anti-correlated (i.e., the movement of the ions in opposite directions). Therefore, as suggested by eqn (4), the cation-cation and anion-anion anti-correlations negatively contributed to the ionic conductivity, whereas the cation-anion anti-correlation contributed positively to the ionic conductivity. The negatively large value of $\sigma_{++}^{\text {distinct }} / \sigma_{\text {ion }}$ for [Li(G3)][TFSA] and [Li(G4)][TFSA] indicates that the momentum conservation of the vehicular-type translational motions of a long-lived $[\mathrm{Li}(\text { glyme })]^{+}$complex cation was preserved mainly by other $[\mathrm{Li}(\text { glyme })]^{+}$complex cations. Hence, $\sigma_{+}^{\text {self }}$ is significantly offset by the negative $\sigma_{++}^{\text {distinct }}$, leading to a small contribution of $\sigma_{++}$to $\sigma_{\text {ion }}$. Furthermore, the negative value of $\sigma_{+-} / \sigma_{\text {ion }}$ suggests that $[\mathrm{Li}(\text { glyme })]^{+}$complex cations and [TFSA $]^{-}$anions are generally well-dissociated, and most of the ions do not form persistent ion-pairs, even at high Li salt concentrations. 

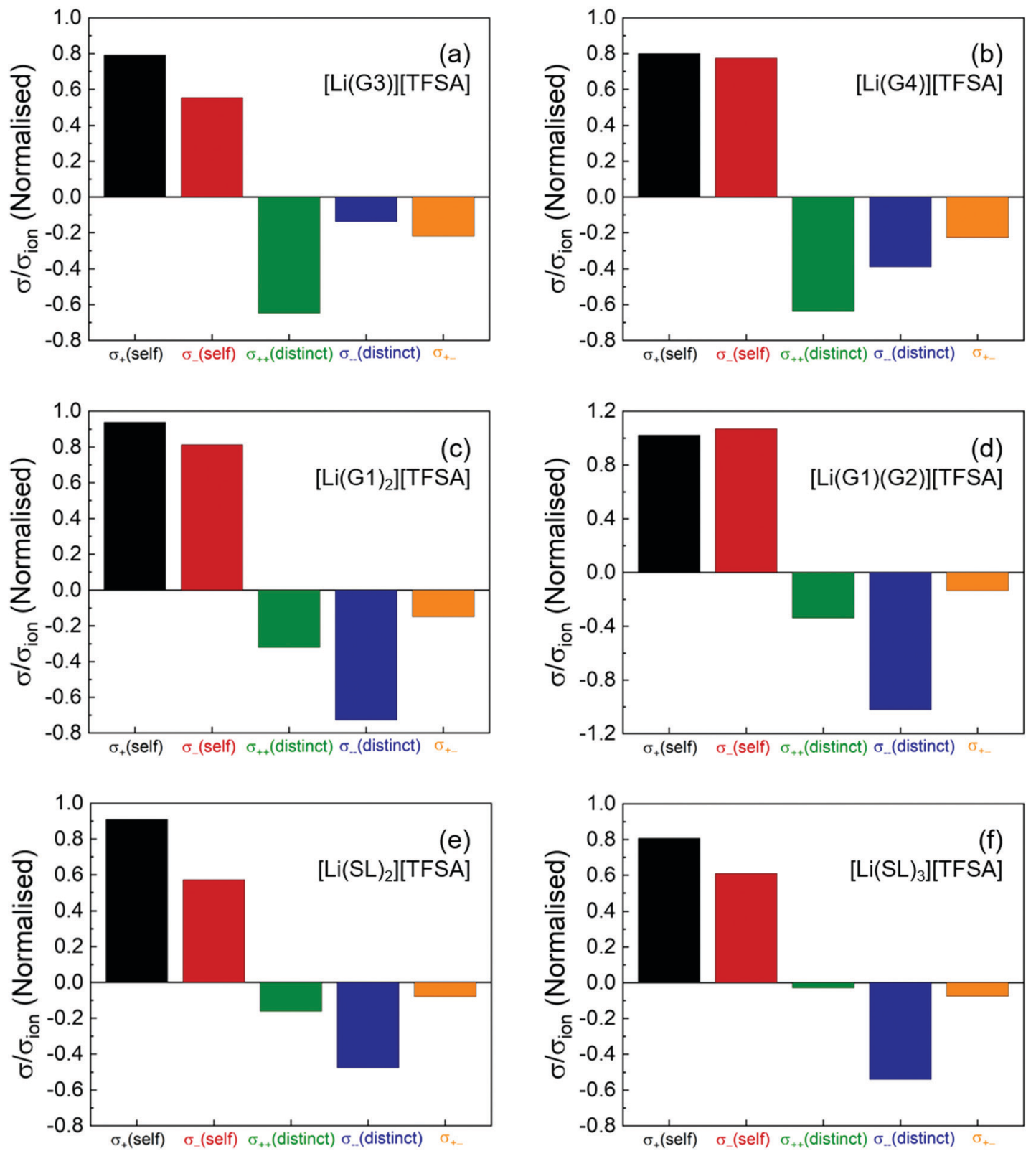

Fig. 2 Five transport coefficients ( $\sigma_{+}^{\text {self }}, \sigma_{-}^{\text {self }}, \sigma_{++}^{\text {distinct }}, \sigma_{--}^{\text {distinct }}$, and $\sigma_{+-}$: left to right) normalised by $\sigma_{\text {ion }}$ of the molten Li salt solvates, (a) [Li(G3)][TFSA], (b) [Li(G4)][TFSA], (c) [Li(G1) 2$][T F S A]$, (d) [Li(G1)(G2)][TFSA], (e) [Li(SL) $\left.{ }_{2}\right][T F S A]$, and (f) [Li(SL) $\left.)_{3}\right]$ TTFSA].

Although our experiments demonstrated the most negatively large value for $\sigma_{++}^{\text {distinct }} / \sigma_{\text {ion }}$ among the cross-correlations, $\sigma_{++}^{\text {distinct }} / \sigma_{\text {ion }}$ was comparable to $\sigma_{--}^{\text {distinct }} / \sigma_{\text {ion }}$ for $[\mathrm{Li}(\mathrm{G} 4)][\mathrm{TFSA}]$ in the reported MD simulations. ${ }^{33}$ Nevertheless, our experimental results on the transport coefficients are in reasonable agreement with the results in the MD simulations. All the distinct terms were found to be negative, and the dynamic cross-correlations of the ions with the same sign was negatively larger than the cationanion cross-correlations for [Li(G4)][TFSA]. The anti-correlations of $[\mathrm{Li}(\mathrm{G} 4)]^{+}$and $[\mathrm{TFSA}]^{-}$in $[\mathrm{Li}(\mathrm{G} 4)][\mathrm{TFSA}]$ was also experimentally verified by the electrophoretic NMR study. ${ }^{38}$ Significant anticorrelations of the ion motions derived from the momentum conservation have been reported for solvent-free ionic liquids and molten salts. ${ }^{35}$ Hence, the strongly anti-correlated motions found in $[\mathrm{Li}(\mathrm{G} 3)][\mathrm{TFSA}]$ and $[\mathrm{Li}(\mathrm{G} 4)][\mathrm{TFSA}]$ corroborate our previous classification of these molten Li salt solvates into a good solvate ionic liquid on the basis of the robustness of [Li(glyme $)]^{+}$complex cations (i.e., long-term coupled motions of Li ion and glyme by diffusivity measurement ${ }^{15}$ and MD simulations ${ }^{39}$ ) and the scarcity of uncoordinated glyme estimated by Raman analysis. ${ }^{40}$

The $\sigma_{++}^{\text {distinct }} / \sigma_{\text {ion }}$ and $\sigma_{+-} / \sigma_{\text {ion }}$ of $\left[\mathrm{Li}(\mathrm{G} 1)_{2}\right][$ TFSA $]$ and [Li(G1)(G2)][TFSA] with shorter glymes are less negative than those of [Li(G3)][TFSA] and [Li(G4)][TFSA] (Fig. 2c and d). This may be due to the occurrence of much faster ligand (glyme) exchange in the shorter glyme-based molten Li salt solvates. ${ }^{16}$ Shorter glymes with a high exchange rate (or a short residence 
time with the Li ion) enables the momentum exchange between the ions and the ligands to satisfy the momentum conservation, and thus the cation-cation and cation-anion correlations are less anti-correlated. ${ }^{26}$ Interestingly, $\sigma_{++}^{\text {distinct }} / \sigma_{\text {ion }}$ and $\sigma_{+-} / \sigma_{\text {ion }}$ of the SL-based electrolytes are even less negative than those of $\left[\mathrm{Li}(\mathrm{G} 1)_{2}\right][\mathrm{TFSA}]$ and $[\mathrm{Li}(\mathrm{G} 1)(\mathrm{G} 2)][\mathrm{TFSA}]$ and approach zero with a small increase in the $\mathrm{SL}$ content from $\left[\mathrm{Li}(\mathrm{SL})_{2}\right][\mathrm{TFSA}]$ to $\left[\mathrm{Li}(\mathrm{SL})_{3}\right][\mathrm{TFSA}]$ (Fig. 2e and f). This means that, despite high Li salt concentrations similar to the glyme systems, the cationcation and cation-anion motions are found to be less anticorrelated for $\left[\mathrm{Li}(\mathrm{SL})_{2}\right][\mathrm{TFSA}]$ and nearly non-correlated for $\left[\mathrm{Li}(\mathrm{SL})_{3}\right][\mathrm{TFSA}]$. The postulated Li ion hopping/exchange conduction mechanism through the unique SL-bridged, chain-like Li-ion coordination structure may be responsible for the insignificant anti-correlations even at high $\mathrm{Li}$ salt concentrations as well as a large contribution of $\sigma_{+}^{\text {self }}$ to $\sigma_{\text {ion. }}{ }^{17,18}$

In addition, the $\sigma_{--}^{\text {distinct }} / \sigma_{\text {ion }}$ of the shorter glyme-based and the SL-based electrolytes is more negative than that of [Li(G3)][TFSA] and [Li(G4)][TFSA]. This suggests that the momentum of bulky TFSA anions is predominantly self-compensated in these molten Li salt solvates with the labile Li ion coordination structures. The negative contribution of $\sigma_{--}^{\text {distinct }}$ significantly offsets the positive contribution of $\sigma_{-}^{\text {self }}$, and thus, $\sigma_{--}$has only a minor effect on $\sigma_{\text {ion }}$ in these molten Li salt solvates.

\subsection{Effects of dynamic correlations of the ions on $\mathrm{Li}^{+}$ transference number}

Herein, we discuss the influence of the dynamic ion correlations in the molten $\mathrm{Li}$ salt solvates on the $\mathrm{Li}^{+}$transference number. The $\mathrm{Li}^{+}$transference number determined from the potentiostatic polarisation method $\left(t_{\mathrm{Li}}^{\mathrm{PP}}\right)$ is considered to be equivalent to that estimated from the MD simulations under anion-blocking conditions $\left(t_{\mathrm{Li}}^{\mathrm{MD}}\right)$ and is rationalised with the Onsager transport coefficients as follows, ${ }^{25}$

$$
\begin{gathered}
t_{\mathrm{Li}}^{\mathrm{PP}}=\frac{\beta^{2}-4 \alpha+4 \alpha^{2}}{4(1-\alpha)(\beta-1)} \\
\alpha=\frac{\sigma_{++}}{\sigma_{++}+\sigma_{--}}, \quad \beta=\frac{2 \sigma_{+-}}{\sigma_{++}+\sigma_{--}}
\end{gathered}
$$

The parameter $\alpha$ must be equal to $t_{\mathrm{Li}}^{\mathrm{NMR}}$ for non-correlated ideal systems, but is greatly affected by the cation-cation crosscorrelation for the molten Li salt solvates, whereas the parameter $\beta$ is dependent on the cation-anion cross-correlation. The parameters $\alpha$ and $\beta$ for the molten Li salt solvates are listed in Table 2. Based on eqn (5), $t_{\mathrm{Li}}^{\mathrm{PP}}$ was simulated versus $\beta$ for different $\alpha$ values, as in Fig. 3; in this figure, the experimental values of $[\mathrm{Li}(\mathrm{G} 4)][\mathrm{TFSA}],[\mathrm{Li}(\mathrm{G} 1)(\mathrm{G} 2)][\mathrm{TFSA}]$ and $\left[\mathrm{Li}(\mathrm{SL})_{3}\right][\mathrm{TFSA}]$ are also plotted.

For the glyme-based electrolytes, the $\alpha$ value of [Li(G3)][TFSA] and $[\mathrm{Li}(\mathrm{G} 4)][\mathrm{TFSA}]$ is significantly lower than that of $\left[\mathrm{Li}(\mathrm{G} 1)_{2}\right][\mathrm{TFSA}]$ and $[\mathrm{Li}(\mathrm{G} 1)(\mathrm{G} 2)][\mathrm{TFSA}]$. This is mainly attributed to the stronger anti-correlated motions of $\mathrm{Li}$ ions in the molten $\mathrm{Li}$ solvates with longer glymes (Fig. 2a and b). The decreased $\sigma_{--}$ due to the highly negative $\sigma_{--}^{\text {distinct }}$ also contributes to higher $\alpha$ values for $\left[\mathrm{Li}(\mathrm{G} 1)_{2}\right][$ TFSA $]$ and $[\mathrm{Li}(\mathrm{G} 1)(\mathrm{G} 2)][\mathrm{TFSA}]$. The strength
Table $2 \alpha$ and $\beta$ of the molten Li salt solvates

\begin{tabular}{lll}
\hline Sample & $\alpha$ & $\beta$ \\
\hline$[\mathrm{Li}(\mathrm{G} 3)][$ TFSA] & 0.25 & -0.78 \\
{$[\mathrm{Li}(\mathrm{G} 4)][$ TFSA $]$} & 0.29 & -0.83 \\
{$\left[\mathrm{Li}(\mathrm{G} 1)_{2}\right][$ TFSA $]$} & 0.88 & -0.43 \\
{$[\mathrm{Li}(\mathrm{G} 1)(\mathrm{G} 2)][\mathrm{TFSA}]$} & 0.93 & -0.37 \\
{$\left[\mathrm{Li}(\mathrm{SL})_{2}\right][$ TFSA] } & 0.89 & -0.19 \\
{$\left[\mathrm{Li}(\mathrm{SL})_{3}\right][$ TFSA] } & 0.92 & -0.18
\end{tabular}

of the cation-anion anti-correlations are well manifested in the order of $\beta$ values - [Li(G4)][TFSA] with the most pronounced cation-cation anti-correlations has the lowest $\beta$ value of -0.83 . Similar $\beta$ values $(-0.87$ for $[\mathrm{Li}(\mathrm{G} 4)][\mathrm{TFSA}]$ and $\sim-0.5$ for $\left[\mathrm{Li}(\mathrm{G} 1)_{2}\right][\mathrm{TFSA}]$ and $\left.[\mathrm{Li}(\mathrm{G} 1)(\mathrm{G} 2)][\mathrm{TFSA}]\right)$ were reported in the MD simulation study. ${ }^{26,33}$ As seen in Fig. 3, both low $\alpha$ and $\beta$ values are responsible for the extremely low $t_{\mathrm{Li}}^{\mathrm{PP}}$ for [Li(G4)][TFSA]. Consequently, we experimentally confirmed Bedrov's notion that $t_{\mathrm{Li}}^{\mathrm{PP}}$ can increase for shorter glyme systems with the weaker Li ionsolvent interaction, in which the momentum conservation-derived ionic anti-correlations of cation-cation and cation-anion motions were suppressed to some extent by the fast solvent (momentum) exchange, leading to the higher $\alpha$ and $\beta$ values.

For the SL-based electrolytes, the $\alpha$ values are comparable to that of the shorter glyme-based electrolytes, but the $\beta$ values are higher than that of the shorter glyme-based electrolytes. The high $\alpha$ value arises from not only the large contribution of $\sigma_{+}^{\text {self }}$ (due to higher $D_{\mathrm{Li}}$ than $D_{\text {anion}}$ ), but also the significantly less-pronounced cation-cation anti-correlations. In a comparison between the shorter glyme based electrolytes and the SL-based electrolytes with the high $\alpha$ values of $\sim 0.9$ (Fig. 3 ), the higher $\beta$ value (due to weaker cation-anion anti-correlations) for the SL-based electrolytes exerts an efficient contribution to $t_{\mathrm{Li}}^{\mathrm{PP}}$ becoming high. As a result, the Li ion hopping/exchange mechanism through the labile SL-bridged, chain-like Li-ion coordination structure may reduce the cation-cation and cation-anion anticorrelations, and impart the high $\alpha$ value and the $\beta$ value closer to zero, enabling a high $t_{\mathrm{Li}}^{\mathrm{PP}}$.

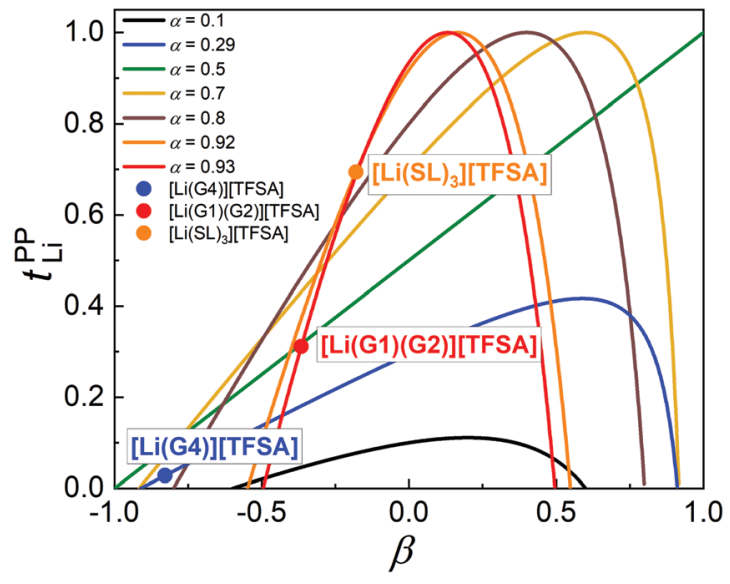

Fig. 3 Plots of $t_{\mathrm{Li}}^{\mathrm{PP}}$ versus $\beta$ with different $\alpha$. The data for [Li(G4)][TFSA], $[\mathrm{Li}(\mathrm{G} 1)(\mathrm{G} 2)][\mathrm{TFSA}]$ and $\left[\mathrm{Li}(\mathrm{SL})_{3}\right][\mathrm{TFSA}]$ are also plotted in the figure. 
The simulation of $t_{\mathrm{Li}}^{\mathrm{PP}}$ with different parameters of $\alpha$ and $\beta$ (Fig. 3) provides an important guideline for designing liquid electrolytes with high $t_{\mathrm{Li}}^{\mathrm{PP}}$, and suggests that single ion conductors $\left(t_{\mathrm{Li}}^{\mathrm{PP}} \sim 1\right)$ can be prepared even with low molecular weight solvents and $\mathrm{Li}$ salts when liquid electrolytes have appropriate values of $\alpha(>0.5)$ and $\beta$. For instance, one can expect an even higher $t_{\mathrm{Li}}^{\mathrm{PP}}$ for the SL-based electrolytes if the $\beta$ parameter approaches zero. This might be achieved either by decreasing the interactions between $\mathrm{Li}$ ions and SL solvents to facilitate solvent-derived momentum exchange (e.g., partial fluorination of SL), or by increasing the cation-anion interactions to some extent (e.g., use of more associative Li salt than LiTFSA). Both would contribute to an increase in $\beta$. Indeed, $t_{\mathrm{Li}}^{\mathrm{PP}}$ increased from 0.68 for $\left[\mathrm{Li}(\mathrm{SL})_{2}\right][\mathrm{TFSA}]$ to 0.77 for $\left[\mathrm{Li}(\mathrm{SL})_{2}\right]\left[\mathrm{BF}_{4}\right]^{17}$ with reprising weakly coordinating, bulky TFSA anions by more strongly Lewis basic, smaller $\mathrm{BF}_{4}$ anions.

\section{Conclusions}

$t_{\mathrm{Li}}^{\mathrm{PP}}$ of the glyme- and SL-based molten solvates was determined by potentiostatic polarisation method. The dynamic ion correlations of each electrolyte were also experimentally studied on the basis of Rolling and Bedrov's concentrated solution theory, and the effects of these correlations on $t_{\mathrm{Li}}^{\mathrm{PP}}$ were discussed. For [Li(G3)][TFSA] and [Li(G4)][TFSA], the negatively large value of $\sigma_{++}^{\text {distinct }} / \sigma_{\text {ion }}$ and $\sigma_{+-} / \sigma_{\text {ion }}$ indicates strong anti-correlations of cation-cation and cation-anion motions, and may be attributed to the momentum conservation of the $[\mathrm{Li}(\text { glyme })]^{+}$complex cation and TFSA $^{-}$anions, preserved solely by the momentum exchange of the ions. These results verified that [Li(G3)][TFSA] and $[\mathrm{Li}(\mathrm{G} 4)][\mathrm{TFSA}]$ showed ionic liquid-like ionic transport behaviour, which in turn led to the extremely low value of $t_{\mathrm{Li}}^{\mathrm{PP}}$. For $\left[\mathrm{Li}(\mathrm{G} 1)_{2}\right][\mathrm{TFSA}]$ and $[\mathrm{Li}(\mathrm{G} 1)(\mathrm{G} 2)][\mathrm{TFSA}], \sigma_{++}^{\text {distinct }} / \sigma_{\text {ion }}$ and $\sigma_{+-} /$ $\sigma_{\text {ion }}$ were found to be less negative, and the $t_{\mathrm{Li}}^{\mathrm{PP}}$ values was higher than those of [Li(G3)][TFSA] and [Li(G4)][TFSA]. This was probably due to the more frequent solvent exchange between the unstable $[\mathrm{Li}(\text { glyme })]^{+}$complex cations. Overall, our experimental results on $t_{\mathrm{Li}}^{\mathrm{PP}}$ and the dynamic ion correlations agreed reasonably with the results obtained from the MD simulations. For the SL-based electrolytes, $\sigma_{++}^{\text {distinct }} / \sigma_{\text {ion }}$ and $\sigma_{+-} / \sigma_{\text {ion }}$ were even less negative and approached zero, indicative of the insignificant anti-correlations of cation-cation and cationanion motions. It was suggested that the $\mathrm{Li}$ ion hopping/ exchange conduction mechanism through the SL-bridged, chain-like Li-ion coordination structure plays an important role in suppressing the cation-cation and cation-anion anticorrelations and displaying a high $t_{\mathrm{Li}}^{\mathrm{PP}}$. As a result, the difference in the ion-solvent interactions and the Li ion coordination structure of the molten Li salt solvates has a significant impact on the cross-correlations of ion motions, which in turn become a critical determinant for $t_{\mathrm{Li}}^{\mathrm{PP}}$. The present study on dynamic ion correlations unveiled the difference in the ion conduction mechanism in some of the molten Li salt solvate electrolytes and its relevance to $\mathrm{Li}^{+}$transference number. Further systematic studies on the ion dynamics in different electrolyte systems would offer insight into a rational design concept for single ion conducting liquid electrolytes.

\section{Conflicts of interest}

There are no conflicts to declare.

\section{Acknowledgements}

This study was supported in part by the JSPS KAKENHI (Grant No. $16 \mathrm{H} 06053,19 \mathrm{~K} 22216$ and $20 \mathrm{H} 02837$ to K. U., $18 \mathrm{H} 03926$ to K. D. and $15 \mathrm{H} 05758$ to M. W.) from the Japan Society for the Promotion of Science (JSPS), and by JST ALCA-SPRING Grant Number JPMJAL1301, Japan.

\section{References}

1 K. M. Diederichsen, E. J. McShane and B. D. McCloskey, ACS Energy Lett., 2017, 2, 2563-2575.

2 P. Barai, K. Higa and V. Srinivasan, J. Electrochem. Soc., 2018, 165, A2654-A2666.

3 Y. Kato, S. Hori, T. Saito, K. Suzuki, M. Hirayama, A. Mitsui, M. Yonemura, H. Iba and R. Kanno, Nat. Energy, 2016, 1, 16030.

4 Y.-G. Lee, S. Fujiki, C. Jung, N. Suzuki, N. Yashiro, R. Omoda, D.-S. Ko, T. Shiratsuchi, T. Sugimoto, S. Ryu, J. H. Ku, T. Watanabe, Y. Park, Y. Aihara, D. Im and I. T. Han, Nat. Energy, 2020, 5, 299-308.

5 Y. Yamada, M. Yaegashi, T. Abe and A. Yamada, Chem. Commun., 2013, 49, 11194-11196.

6 Y. Yamada, K. Furukawa, K. Sodeyama, K. Kikuchi, M. Yaegashi, Y. Tateyama and A. Yamada, J. Am. Chem. Soc., 2014, 136, 5039-5046.

7 J. Qian, W. A. Henderson, W. Xu, P. Bhattacharya, M. Engelhard, O. Borodin and J.-G. Zhang, Nat. Commun., 2015, 6, 6362.

8 L. Suo, W. Xue, M. Gobet, S. G. Greenbaum, C. Wang, Y. Chen, W. Yang, Y. Li and J. Li, Proc. Natl. Acad. Sci. U. S. A., 2018, 115, 1156-1161.

9 H. Yoon, P. Howlett, A. S. Best, M. Forsyth and D. R. Macfarlane, J. Electrochem. Soc., 2013, 160, A1629.

10 X. Gao, F. Wu, A. Mariani and S. Passerini, ChemSusChem, 2019, 12, 4185-4193.

11 L. Suo, Y.-S. Hu, H. Li, M. Armand and L. Chen, Nat. Commun., 2013, 4, 1481.

12 D. W. McOwen, D. M. Seo, O. Borodin, J. Vatamanu, P. D. Boyle and W. A. Henderson, Energy Environ. Sci., 2014, 7, 416-426.

13 L. Suo, O. Borodin, T. Gao, M. Olguin, J. Ho, X. Fan, C. Luo, C. Wang and K. Xu, Science, 2015, 350, 938-943.

14 K. Yoshida, M. Nakamura, Y. Kazue, N. Tachikawa, S. Tsuzuki, S. Seki, K. Dokko and M. Watanabe, J. Am. Chem. Soc., 2011, 133, 13121-13129.

15 K. Ueno, K. Yoshida, M. Tsuchiya, N. Tachikawa, K. Dokko and M. Watanabe, J. Phys. Chem. B, 2012, 116, 11323-11331.

16 C. Zhang, K. Ueno, A. Yamazaki, K. Yoshida, H. Moon, T. Mandai, Y. Umebayashi, K. Dokko and M. Watanabe, J. Phys. Chem. B, 2014, 118, 5144-5153. 
17 K. Dokko, D. Watanabe, Y. Ugata, M. L. Thomas, S. Tsuzuki, W. Shinoda, K. Hashimoto, K. Ueno, Y. Umebayashi and M. Watanabe, J. Phys. Chem. B, 2018, 122, 10736-10745.

18 A. Nakanishi, K. Ueno, D. Watanabe, Y. Ugata, Y. Matsumae, J. Liu, M. L. Thomas, K. Dokko and M. Watanabe, J. Phys. Chem. C, 2019, 123, 14229-14238.

19 K. Yoshida, M. Tsuchiya, N. Tachikawa, K. Dokko and M. Watanabe, J. Electrochem. Soc., 2012, 159, A1005-A1012.

20 M. Yanagi, K. Ueno, A. Ando, S. Li, Y. Matsumae, J. Liu, K. Dokko and M. Watanabe, J. Electrochem. Soc., 2020, 167, 070531.

21 D. M. Pesko, K. Timachova, R. Bhattacharya, M. C. Smith, I. Villaluenga, J. Newman and N. P. Balsara, J. Electrochem. Soc., 2017, 164, E3569-E3575.

22 I. Villaluenga, D. M. Pesko, K. Timachova, Z. Feng, J. Newman, V. Srinivasan and N. P. Balsara, J. Electrochem. Soc., 2018, 165, A2766-A2773.

23 M. D. Galluzzo, J. A. Maslyn, D. B. Shah and N. P. Balsara, J. Chem. Phys., 2019, 151, 020901.

24 L. A. Woolf and K. R. Harris, J. Chem. Soc., Faraday Trans. 1, 1978, 74, 933-947.

25 F. Wohde, M. Balabajew and B. Roling, J. Electrochem. Soc., 2016, 163, A714-A721.

26 D. Dong, F. Sälzer, B. Roling and D. Bedrov, Phys. Chem. Chem. Phys., 2018, 20, 29174-29183.

27 N. M. Vargas-Barbosa and B. Roling, ChemElectroChem, 2020, 7, 367-385.

28 P. G. Bruce, J. Evans and C. A. Vincent, Solid State Ionics, 1988, 28, 918-922.
29 M. Watanabe, S. Nagano, K. Sanui and N. Ogata, Solid State Ionics, 1988, 28-30, 911-917.

30 H. Moon, R. Tatara, T. Mandai, K. Ueno, K. Yoshida, N. Tachikawa, T. Yasuda, K. Dokko and M. Watanabe, J. Phys. Chem. C, 2014, 118, 20246-20256.

31 S. Zugmann, M. Fleischmann, M. Amereller, R. M. Gschwind, H. D. Wiemhöfer and H. J. Gores, Electrochim. Acta, 2011, 56, 3926-3933.

32 M. Gouverneur, J. Kopp, L. van Wüllen and M. Schönhoff, Phys. Chem. Chem. Phys., 2015, 17, 30680-30686.

33 D. Dong and D. Bedrov, J. Phys. Chem. B, 2018, 122, 9994-10004.

34 O. Borodin, J. Self, K. A. Persson, C. Wang and K. Xu, Joule, 2020, 4, 69-100.

35 H. K. Kashyap, H. V. Annapureddy, F. O. Raineri and C. J. Margulis, J. Phys. Chem. B, 2011, 115, 13212-13221.

36 K. R. Harris and M. Kanakubo, J. Chem. Eng. Data, 2016, 61, 2399-2411.

37 J. Alvarado, M. A. Schroeder, M. Zhang, O. Borodin, E. Gobrogge, M. Olguin, M. S. Ding, M. Gobet, S. Greenbaum, Y. S. Meng and K. Xu, Mater. Today, 2018, 21, 341-353.

38 F. Schmidt and M. Schönhoff, J. Phys. Chem. B, 2020, 124, 1245-1252.

39 W. Shinoda, Y. Hatanaka, M. Hirakawa, S. Okazaki, S. Tsuzuki, K. Ueno and M. Watanabe, J. Chem. Phys., 2018, 148, 193809.

40 K. Ueno, R. Tatara, S. Tsuzuki, S. Saito, H. Doi, K. Yoshida, T. Mandai, M. Matsugami, Y. Umebayashi, K. Dokko and M. Watanabe, Phys. Chem. Chem. Phys., 2015, 17, 8248-8257. 